\title{
IMPORTANCIA DE LA POBLACIÓN FLOTANTE EN LOS MUNICIPIOS RURALES DEL INTERIOR PENINSULAR. ANÁLISIS DE LA SITUACIÓN EN CASTILLA Y LEÓN ${ }^{1}$
}

\author{
José Ma Delgado Urrecho y Luis Carlos Martínez Fernández \\ Departamento de Geografía. Universidad de Valladolid \\ jose@fyl.uva.es, luiscar@fyl.uva.es
}

\section{RESUMEN}

Los municipios rurales de Castilla y León se han caracterizado por una continuada pérdida de población, primero como consecuencia del éxodo masivo $\mathrm{y}$, actualmente, por una dinámica natural regresiva. Sin embargo, y como aspecto a destacar positivamente, existe un aporte demográfico no contabilizado. Los datos manejados revelan que durante el verano, particularmente, los residentes en estos ámbitos llegan a duplicarse holgadamente. Una realidad a tener en cuenta por su efecto socioeconómico dinamizador, ante el extraordinario número de municipios incapaces de mantener recursos y prestar servicios.

Palabras clave: Población, poblamiento, Castilla y León, administración local, gobierno del territorio.

\footnotetext{
ABSTRACT

Rural municipalities of Castilla y León have been characterized by a continued loss of population, first as a result of mass exodus and, at present time, by a regressive nature dynamic. However, and as a positive aspect to emphasize, there is demographic contribution

Fecha de recepción: julio 2012.

Fecha de aceptación: julio 2013.

1 Este artículo ha sido posible gracias al contrato Art.83 firmado entre el Consejo Económico y Social de Castilla y León y la Fundación General de la Universidad de Valladolid para la elaboración del Informe sobre Población y Poblamiento en Castilla y León ( $\mathrm{N}^{\mathrm{o}}$ Proyecto 7476, Cod.Interno 061/102882), dirigido por el Dr.D.José Ma Delgado Urrecho.
} 
unaccounted. Used data reveal that during the summer, particularly, residents in these areas reach double amply. A fact to consider for its socioeconomic dynamic effect, in the face of the extraordinary number of municipalities, unable to keep resources and provide services.

Key words: Population, settlement model, Castilla y León (Spain), local management, territory governance.

\section{INTRODUCCIÓN}

Las pérdidas demográficas en los pequeños municipios del ámbito rural han sido una constante histórica desde hace más de un siglo, y a la par que la población española aumentaba un $151 \%$ entre 1900 y 2011 los centros de servicios de entre cinco mil y diez mil habitantes apenas lo hicieron un 17\%, reduciéndose los residentes en municipios menores de esa entidad en el 36\%. Si a comienzos del siglo XX habitaba en ellos la mitad de la población española, a mediados lo hacía tan sólo un tercio y en estos momentos la proporción no alcanza siquiera el 13\%, consecuencia de un modelo de poblamiento cada vez más concentrado en las franjas costeras, las grandes y medianas ciudades del interior y los principales valles fluviales (Goerlich y Mas, 2006). Pese a ello, el número de estos pequeños municipios del interior era en 2011 muy similar al de 1900 -un 8\% inferior-, dando como resultado la existencia de amplios territorios caracterizados por la presencia de poblaciones dispersas en un excesivo número de núcleos, con pirámides etarias invertidas, típicas de un envejecimiento extremo, necesidades crecientes de servicios sociales y sanitarios, así como una reducida capacidad económica. Las cifras del Padrón Municipal de Habitantes son suficientemente elocuentes con respecto al futuro de tales enclaves pero, no obstante, enmascaran otras realidades que, ajenas a la simple lógica de la estadística oficial, pueden ayudar a entender su supervivencia. En este sentido, la situación del medio rural castellano y leonés supone un ejemplo paradigmático, al alcanzar densidades de población mínimas a escala de la Unión Europea -12,4 habitantes $/ \mathrm{km}^{2}$ - y pertenecer el $99 \%$ de sus municipios a este ámbito frente al $91 \%$ del promedio nacional. Es más, si en España los que no llegan al millar de residentes suponen el $60 \%$ del total, en Castilla y León son un $88 \%$ y en ellos la densidad es de 6,9 habitantes $/ \mathrm{km}^{2}$, con una población media de 244 residentes cuyo índice de envejecimiento se cifra en cinco mayores de 65 años por cada menor de 16. Un conjunto formado por 1.977 municipios, el $41 \%$ de los existentes en el país con semejantes características, que abarcan las tres cuartas partes del territorio regional.

La pervivencia de estos municipios tan escasamente poblados difícilmente se explicaría en virtud de su propia dinámica interna, dependiendo de factores exógenos ligados a una «economía de temporada» que acrecienta notablemente la cifra de residentes no empadronados durante periodos vacacionales: una población flotante englobada en el concepto incorporado al Censo de Población de 2001 bajo la denominación de «población vinculada»; en otras palabras y tal como la define este documento, «el conjunto de personas censables que tienen algún tipo de vinculación habitual con el municipio en cuestión, ya sea porque residen allí, porque trabajan o estudian allí, o porque, no siendo su residencia habitual, suelen pasar allí ciertos periodos de tiempo (veraneos, puentes, fines de semana...)» (INE, 2001: 22). A la espera de los resultados del Censo de 2011, la creciente importancia de esa contribución 
externa puede ser estimada a través de otras fuentes, como la Encuesta de Infraestructuras y Equipamientos Locales del Ministerio de Hacienda y Administraciones Públicas. Sus datos sobre el máximo estacional de población, si bien no coinciden exactamente con el concepto de población vinculada, sí permiten establecer la intensidad del fenómeno analizado en fechas más recientes, concretamente las referidas a 2010. Por último, métodos indirectos como el estudio de la disponibilidad de viviendas familiares y secundarias o la ocupación hotelera posibilitan acercar al presente los proporcionados por las fuentes estadísticas mencionadas $^{2}$.

El acercamiento a la realidad de este aporte exógeno requiere cuando menos dos vías, la del turismo reglado o colectivo, bien conocido a través de los registros de pernoctaciones por el pago de servicios en sus diferentes modalidades (hoteles, pensiones, campings, casas rurales, etc.) y el privado o residencial, que admite asimismo múltiples opciones (segunda residencia, alquiler, vivienda familiar, cesión del alojamiento, etc.). El primero de ellos no presenta excesivos problemas en su análisis, que puede realizarse a través de las estadísticas recogidas por diversos organismos y, en especial, por el Instituto de Estudios Turísticos, pero la cuantificación del residencial es en principio más dificultosa, al depender de datos indirectos y encuestas. Su componente interior resulta predominante, como demuestra el que entre los españoles el alojamiento privado alcance el $88 \%$ del total, frente al $31 \%$ correspondiente a los extranjeros, en gran parte debido a la importancia de los desplazamientos de corta estancia (fines de semana y «puentes»). Un alojamiento que responde, además, a múltiples tipologías, desdibujando los límites entre ambos conjuntos (Rodríguez-Salmones, Cabeza, Aranda y Garrido, 2003)3 . Tanto más en Castilla y León, donde la importancia de este turismo no reglado es mayor como consecuencia del mantenimiento de lazos familiares entre residentes en el medio urbano y rural en una proporción que, al tratarse de una región emigrante, supera a otras en este aspecto, al igual que sucede en cuanto a la retención de la propiedad de viviendas rurales en manos de emigrantes afincados desde hace décadas en el medio urbano, ya residan actualmente dentro o fuera de la Comunidad Autónoma, todo ello en un país donde la tenencia de una segunda residencia es un fenómeno relativamente generalizado (García, Cebrián y Panadero, 2008) ${ }^{4}$. Se trata además de un territorio con elevada capacidad de atracción en lo que respecta al turismo interior, el tercero a escala nacional y el primero en cuando al saldo de entradas y salidas (más de siete millones), así como de pernoctaciones en alojamientos de turismo rural, recibiendo cerca de dieciséis millones de personas procedentes de otros núcleos de la misma o de otras CC.AA., siguiendo una tendencia al alza que sólo se vio interrumpida de forma puntual en el año 2007 y, si bien la reducción del saldo fue ínfima, también en $2011^{5}$.

2 En realidad la población vinculada según la definición lel INE tampoco mide con exactitud la carga demográfica real en los municipios españoles, siendo recomendable la utilización de otras fuentes complementarias (Alberich González, 2009).

3 El concepto de alojamiento colectivo o privado es confuso (una casa rural puede considerarse alojamiento colectivo por la Administración y privado por el turista), el encuestador puede errar al asignarlo a una tipología, la naturaleza jurídica del propietario también influye (alquiler de una casa particular que esté registrada como casa rural o no), etc.

4 En 2006 el 20,7\% de los hogares españoles disponían de al menos una segunda vivienda.

5 Castilla y León recibió en 2011 el 10,8\% de los viajes internos y emitió el 6,2\%, frente al 11,9\% y 7,2\% en 2010 (Instituto de Estudios Turísticos: Balance del Turismo Año 2011. Resultados de la actividad turística en 
A estos dos enfoques relativos al aporte externo de carácter temporal a la población residente en municipios rurales ha de sumarse un tercero, dirigido a conocer la realidad demográfica de un territorio definido en este sentido por el intenso envejecimiento de sus habitantes, su constante pérdida de efectivos como consecuencia tanto de los saldos naturales como migratorios y la escasa entidad de la inmensa mayoría de los núcleos que lo conforman, todo ello en unos momentos en que la redefinición del mapa de las administraciones locales surge como uno de los puntos fundamentales en la ordenación territorial, aspecto que sin ser novedoso - mucho menos en Castilla y León, dada la extrema fragmentación espacial y elevado número de municipios-, se ve incentivado por la actual crisis económica, presionando a la toma de iniciativas conducentes a una nueva distribución de competencias que permita el mejor aprovechamiento de los recursos y la generación de economías de escala, todo ello sin menoscabo de la prestación de servicios. Puzle de difícil encaje y que, desde una perspectiva geográfica, no puede ni debe intentar solucionarse exclusivamente mediante la aplicación de mínimos de población, debiendo atender a otros parámetros derivados de la situación particular en cada comunidad autónoma y comarca. Y entre ellos, la importancia de esta población flotante ha de ser sin duda considerada con el objeto de conocer su auténtica viabilidad económica.

\section{EL APORTE DE UN TURISMO INTERIOR ESTRECHAMENTE RELACIONADO CON LA «DIÁS- PORA» MIGRATORIA}

El carácter estacional del turismo interior en Castilla y León responde, al igual que en otras CC.AA., a los periodos vacacionales, si bien su distribución temporal muestra rasgos propios. Las variaciones mensuales de los desplazamientos señalan picos destacados en torno a los meses de marzo y abril, por la Semana Santa, y agosto, debido a las vacaciones estivales. El máximo anual corresponde a estas últimas, concentrando entre julio y agosto el 22,9\% de las visitas (3,6 millones en 2011), proporción algo inferior al promedio nacional $-24,2 \%-y$, por supuesto, alejada de la registrada en los principales destinos del turismo de playa, como Baleares, donde en estos dos meses suman el 34,6\% de la afluencia turística, Cantabria $(32,1 \%)$ o la Comunidad Valenciana $(30,4 \%)$, entre otras. El mes de agosto es sin duda el más destacado y sitúa a Castilla y León en el cuarto lugar en términos absolutos, tras Andalucía, Cataluña y Valencia. Pero durante la Semana Santa la concentración de viajes supera en cambio la media española. Aquéllos con destino en la Comunidad durante el mes correspondiente, generalmente abril -aunque en 2005 y 2009 fue en marzo y en 2010 se distribuyó entre ambos-, fueron el 10,8\% del total anual registrado entre 2005 y 2011, mientras en el conjunto de los desplazamientos interiores en España sumaron un 9,9\%. Solamente Extremadura excede en términos relativos dicha concentración $(11,3 \%)$, pero en cifras absolutas Castilla y León la aventaja ampliamente (1,6 millones en 2011), colocándose en tercer lugar tras Andalucía $(2,6)$ y Cataluña $(2,3)$. Las fiestas nacionales y

\footnotetext{
España). En cifras absolutas el máximo de viajes con destino a esta Comunidad se alcanzó en 2010 (17.205.000), descendiendo en 2011 a 15.769.900, según cifras del IET (COYUNTUR. Boletín trimestral de Coyuntura Turística, $n^{\circ} 9$, I trimestre 2012). El Índice de Tendencias de Competitividad Turística la sitúa en primer lugar en el ranking de 2010 dentro del conjunto del interior peninsular y en el tercero a escala nacional (IET: Encuesta de Movimientos Turísticos de los Españoles. Informe Anual 2010).
} 
regionales implican también un incremento lógico de los desplazamientos, con máximos en el mes de marzo (San José), mayo (Día Internacional de los Trabajadores), octubre (Día de la Hispanidad), noviembre (Todos los Santos) y diciembre (Constitución), especialmente los años en que la cercanía de un fin de semana permite alargar las estancias, rebasando también los índices medios nacionales, hecho que sucede asimismo en las vacaciones navideñas y refuerza en abril, gracias a la fiesta de la Comunidad Autónoma, el turismo atraído por la Semana Santa.

Figura 1

TURISMO INTERIOR EN CASTILLA Y LEÓN. DISTRIBUCIÓN MENSUAL (PROMEDIO 2005-11) Y POR RESIDENCIA (2008)

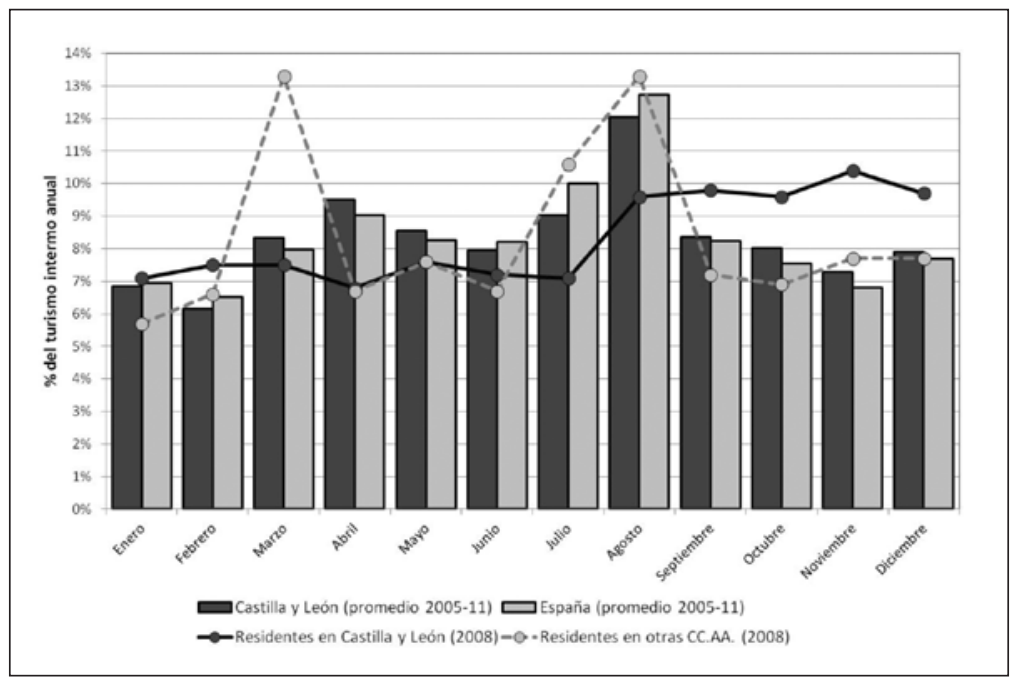

Fuente: Instituto de Estudios Turísticos: FAMILITUR (Informes Anuales 2005 a 2011 y Turismo Interior en Castilla y León en el año 2008.

La intensidad mensual del turismo interior varía no obstante, y de forma sustancial, según los viajeros procedan de la propia Comunidad o de fuera de ella (Fig. 1). Los segundos reflejan mejor la estacionalidad propia de la Semana Santa y el verano, con máximos anuales que superan el 13\% del total de visitas, mientras los castellanos y leoneses aumentan sus desplazamientos a partir de agosto hasta concentrar en torno a un $10 \%$ mensual desde ese mes hasta finalizar el año, aumentando ligeramente en noviembre debido al consabido regreso al domicilio familiar en el Día de Todos los Santos. El turismo interior que transita por Castilla y León recorre distancias cortas o medias al partir predominantemente de las regiones colindantes y en especial de Madrid (un 33\%) y el País Vasco (10\%), así como de la propia Comunidad (30\%), utilizando mayoritariamente el vehículo propio para sus desplazamientos (89\%), la mitad de los cuales se deben a motivos de ocio o vacaciones. Estos se realizan al margen de los paquetes turísticos, organizados por cuenta propia (89\%), con un perfil medio de los participantes correspondiente al de parejas casadas de entre 25 y 44 años con hijos menores de edad y un nivel de estudios medio o superior, que optan por alojarse sobre todo 
en viviendas de familiares o amigos (39\%). Aunque los períodos vacacionales de los castellanos y leoneses coinciden con los flujos de mayor intensidad a escala nacional, las estancias suelen ser cortas, 4,3 noches como media. El 72\% se reducen a tres días o menos, relacionadas por tanto con el aprovechamiento de los fines de semana (el $54 \%$ ) y puentes (4\%). El número medio de pernoctaciones varía no obstante según el tipo de alojamiento, siendo más prologadas cuando se trata de una vivienda alquilada $(6,1)$ que propia o familiar $(4,5$ y 4,3), al ser aprovechadas con mayor intensidad las segundas durante fines de semana, mientras en los alojamientos hoteleros la permanencia es menor $(3,0)$.

\section{Figura 2}

TIPO DE DESPLAZAMIENTO SEGÚN RESIDENCIA DEL VIAJERO (2008)
Figura 3

DISTRIBUCION DE PERNOCTACIONES SEGÚN RESIDENCIA DEL VIAJERO (2008)

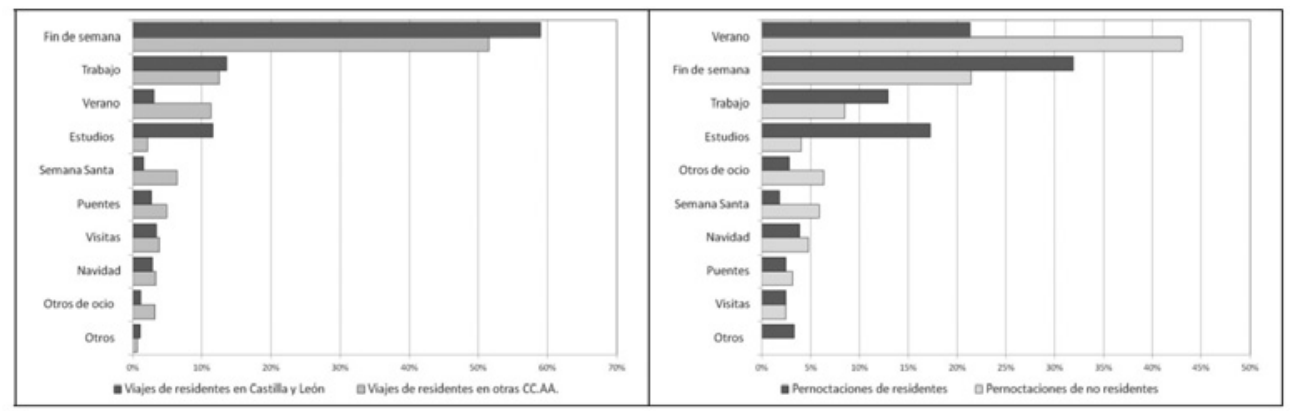

Fuente: Instituto de Estudios Turísticos: Turismo Interior en Castilla y León en el año 2008.

Ahora bien, la distribución mensual no refleja con exactitud la causa real del desplazamiento, ya que éste puede coincidir con períodos vacacionales y ser solamente de fin de semana, por ejemplo. Atendiendo a la tipología del viaje y a la procedencia de los viajeros es posible concretar algo más su incidencia en las variaciones de población y cuándo éstas se producen. Castilla y León muestra bajo tal óptica un fuerte atractivo de cara a los desplazamientos de fin de semana, momento elegido para el 59,0\% de los viajes realizados dentro de la Comunidad y del 51,6\% de los procedentes de fuera de ella (Fig. 2). Un turismo de elevada frecuencia aún más importante si consideramos los puentes, aprovechados por el 2,8\% de los viajeros intrarregionales y por casi el doble de los interregionales $(4,9 \%)$, quienes al tener que recorrer por lo general mayores distancias se sienten asimismo más tentados a elegir los encadenamientos de domingos y festivos. El elevado número de desplazamientos durante los fines de semana es además independiente de su finalidad última, ya se trate de turismo cultural (el 50,7\% de los motivados por este objetivo se hacen en tales días), las visitas a familiares o amigos (el 54,9\%) y, sobre todo, los dedicados al ocio y descanso (74\%). Las vacaciones estacionales, tanto en época estival $(3,1 \%)$, como en Navidad $(2,8 \%)$ o Semana Santa $(1,6 \%)$ tienen menor repercusión entre los empadronados en la Región, pero atraen a los de fuera de ella, siendo el motivo principal del $11,3 \%, 3,4 \%$ y $6,4 \%$ de sus desplazamientos, respectivamente.

No obstante, desde el punto de vista de la repercusión en las economías locales no tiene tanta incidencia el número de viajeros como el tiempo que pasan en los destinos elegidos, 
distribuido de forma muy diferente ${ }^{6}$. Las vacaciones estivales, por su duración, concentran un $36,4 \%$ de las pernoctaciones, mientras las de Semana Santa o Navidad solamente alcanzan como tales el 4,5\%. En cambio, a los fines de semana corresponde un $24,6 \%$ y otro 5,2\% adicional vinculado a los puentes. A éstas se suman las relacionadas con los viajes de trabajo $(9,9 \%)$, las debidas a la realización de estudios $(8,1 \%)$, otros viajes de ocio $(5,2 \%)$ y, finalmente, las visitas a familiares o amigos $(2,5 \%)$. Los tiempos de estancia tampoco son los mismos para los residentes en Castilla y León que para los procedentes de otras CC.AA. (Fig. 3). Los primeros, como es lógico por la proximidad al lugar de destino, sacan más partido de los fines de semana, que concentran el 31,9\%, mientras los foráneos centran su permanencia en las vacaciones de verano $(43,1 \%)$, aunque también es elevado el porcentaje correspondiente a los fines de semana $(21,4 \%)$, probablemente por la disponibilidad de vivienda propia, cedida o familiar.

Todos estos datos confirman la importancia de la población emigrante vinculada aún a su lugar de origen que, tanto si reside actualmente en otras regiones cercanas como en ciudades de Castilla y León, aprovecha los días de asueto para retornar. Madrid es la comunidad autónoma con mayor número de residentes originarios de Castilla y León, 417.112 en 2011, el $37,6 \%$ del total de los que la han abandonado para asentarse en otras, lo cual explica la intensidad de las estancias de corta duración vinculadas al municipio de origen y procedentes de la capital de España, a las cuales se suman las de madrileños poseedores de una segunda residencia en la Comunidad. En 2008 totalizaron 3.165.205 viajes durante los fines de semana, cifra cercana a los realizados por los propios residentes de Castilla y León (3.598.485). En cuanto al País Vasco, se trata del segundo receptor, con 188.733 residentes castellanos y leoneses (el 17,0\%), y al igual que en el caso anterior, su propia población protagoniza también frecuentes desplazamientos ligados al ocio, 989.077, también en sábados y domingos. Otras CC.AA. colindantes aportan, en menor cuantía, flujos similares efectuados por oriundos de Castilla y León, como sucede desde Asturias, Aragón, Galicia, Cantabria, Castilla-La Mancha, Navarra, La Rioja y Extremadura. Resulta algo más problemático establecer cuantitativamente el destino exacto de estos turistas, si bien todo indica que la mayoría se dirigen al medio rural, puesto que un 69\% de los encuestados por el Instituto de Estudios Turísticos afirma dedicarse durante su estancia a pasear por el campo o disfrutar de la naturaleza.

Los visitantes optan por alojarse en viviendas de familiares o propias, siendo en ambos casos cuando las estancias resultan más prolongadas. De los 16,4 millones de turistas llegados en 2008, 6,4 se albergaron en viviendas familiares y 5,7 en propias, concentrando entre ambas modalidades el $74 \%$ de los visitantes (IET, 2008). Las cifras del turismo reglado, siendo elevadas, se encuentran a gran distancia de éstas. Así, los establecimientos hoteleros y similares con registro de estancia hospedaron 1,7 millones de personas, mientras las viviendas en alquiler recibieron 0,9 millones. En las dos variantes se incluye parcialmente el turismo rural, pues teniendo en cuenta las peculiaridades de este sector con respecto a los procedimientos seguidos en el alquiler de habitaciones o viviendas íntegras, su inscripción o

$6 \quad$ Al igual que el número de desplazamientos, el de pernoctaciones también se redujo entre 2010 y 2011 en esta Comunidad, pasando de 71,5 a 64,9 millones, frente a los incrementos logrados en Andalucía, Cataluña y la Comunidad Valenciana, sin que ninguna de ellas logrará no obstante retornar a las cifras de 2010, año durante el cual solamente Castilla y León registró crecimiento (Instituto de Estudios Turísticos: FAMILITUR. Encuesta de Movimientos Turísticos de los Españoles. Informe Anual 2010). 
no como casas rurales y las dificultades del visitante para tipificar la modalidad de estancia, no siempre es posible diferenciar esta tipología con exactitud. Los datos oficiales sitúan a Castilla y León en el primer lugar de España en este formato turístico (Alario, 2006), con 3.053 establecimientos, 27.579 plazas y 593.785 viajeros en 2010, el 22,4\% del total nacional. Aunque buena parte de ellos proceden de la propia Comunidad (17,7\%), Madrid vuelve a ser el principal origen (48,3\%), seguido del País Vasco $(7,0 \%)$ y Galicia $(4,4 \%)$. En total, considerando todos los tipos de alojamientos colectivos, la Comunidad recibió en el citado año más de cuatro millones de viajeros, pues a los procedentes de España ha de añadirse el turismo internacional, que incrementa la cifra final un 19\%. El grado de atracción ejercido sobre este último es bajo en comparación con el total nacional, apenas un 2,4\%, y se caracteriza por una distribución temporal similar a la general en el caso de españoles residentes fuera del país pero no así entre los extranjeros, que concentran sus visitas entre mayo y septiembre, distribuyéndose de forma homogénea durante ese periodo. En cuanto a su procedencia, el turismo reglado interior coincide básicamente con los lugares de origen ya señalados, destacando el llegado de Madrid (26,4\%) y otras comunidades autónomas colindantes, correspondiente a los viajeros de la Región un escaso 17,4\%, en consonancia con sus preferencias por desplazamientos no reglados y la utilización de las viviendas propias o familiares. Se aprecia, no obstante, una mayor participación de turistas andaluces, catalanes y valencianos, cuya presencia es mínima en el caso del turismo no reglado, justificada por la ausencia de una vinculación directa con Castilla y León.

La prevalencia de visitantes llegados de CC.AA. colindantes y, en especial, de quienes poseen una segunda residencia enclavada en Castilla y León, así como el retorno de los emigrados nacidos en la Comunidad y, aún en mayor medida, la propia movilidad espacial de los en ella empadronados, que protagonizan más de la mitad de los viajes (el 55,4\% en 2010), explica el predominio de los alojamientos en viviendas familiares o propias, concentrando en torno a las tres cuartas partes de los visitantes y pernoctaciones (Fig. 4). De los llegados de fuera, la intensidad de la emigración padecida por Castilla y León hacia Madrid, unida a la pujanza turística de la serranía abulense y la abundancia en ella de segundas residencias se traduce en la elevada intensidad alcanzada por el turismo interior en esa comarca, que acumuló más de doce millones de pernoctaciones en 2008. Un atractivo también ejercido por Las Merindades del norte burgalés con respecto a la población vizcaína y por León en Galicia y Asturias. Gracias a estos vínculos de proximidad y migratorios Ávila concentra el $22 \%$ de las estancias, León el $16 \%$ y Burgos el 14\%, mientras Valladolid, la provincia más poblada, solo alcanza un $7 \%$. No sucede lo mismo en el turismo intrarregional, donde sí se aprecia claramente el peso demográfico de cada una de ellas, resultante a su vez de la capacidad de captación de inmigrantes rurales llegados a las ciudades en etapas anteriores. Así, Valladolid acumula el $21 \%$ de esas estancias y Salamanca y León el 19\%, mientras a Ávila sólo corresponde un 7\%.

Se trata, en conclusión, de un turismo estrechamente relacionado con la pervivencia de vínculos de parentesco y la posibilidad de alojamiento gratuito, que si bien en el segundo caso incluye tanto viviendas familiares como segundas residencias propiedad de antiguos emigrantes o de turistas nacidos fuera de la Comunidad, muestra claramente la importancia que el éxodo rural padecido en décadas precedentes mantiene en la dinámica actual de los pequeños municipios castellanos y leoneses, generando flujos capaces de dinamizar la economía local (Alario y Morales, 2012). 


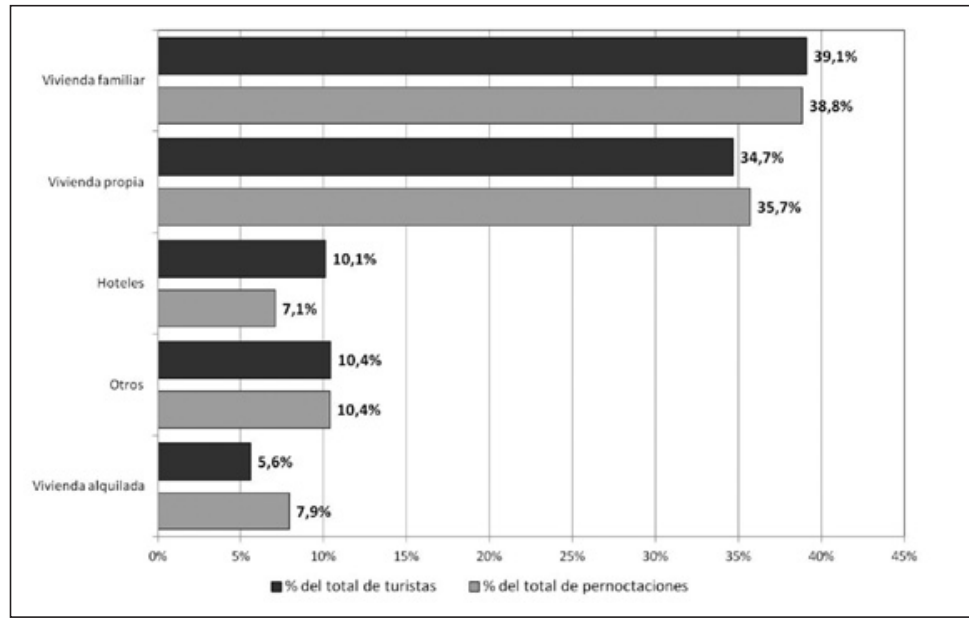

Fuente: Instituto de Estudios Turísticos: FAMILITUR (Movimientos Turísticos de los Españoles. Castilla y León, 2008.

\section{LA ABUNDANTE DISPONIBILIDAD DE VIVIENDAS EN EL MEDIO RURAL}

El análisis del turismo interior, pese a indicarnos la importancia del número de desplazamientos y motivaciones de los mismos, enmascara no obstante el papel jugado por los núcleos rurales como centros receptores, al tratarse de datos a escala provincial o regional, pero no municipal. Además, es preciso analizar tanto el número como la ocupación de las viviendas disponibles, al tratarse del tipo de alojamiento predominante. Una fuente que permite obtener información desglosada de esta variable es el Catastro Inmobiliario Urbano ${ }^{7}$, donde aunque se aportan datos sobre cada uno de los municipios, no suministra el carácter principal o secundario de la residencia, cuya evolución sí puede seguirse a escala provincial a través de la Estimación del Parque de Viviendas ${ }^{8}$. La combinación de todos los parámetros requeridos se ofrece en el Censo de Población y Viviendas, que conlleva el problema de la antigüedad de la información disponible.

A lo largo de la primera década del siglo se aprecia en Castilla y León un incremento notable del número de licencias de construcción de viviendas, alcanzando su máximo en 2006 para caer ligeramente en 2007 y de forma radical en los años siguientes, consecuencia de la crisis inmobiliaria. Entre 2002 y 2009 se concedieron en la Comunidad 135.405 licencias para la construcción de viviendas familiares, de las cuales el 39\% correspondía a unifamiliares (52.930), cuya participación en el total fue aumentando desde un $23 \%$ inicial hasta un máximo del $56 \%$ en 2005 , descendiendo en años posteriores. Gran parte de ellas

7 Ministerio de Economía y Hacienda: Catastro Inmobiliario Urbano. Secretaría de Estado de Hacienda y Presupuestos, Secretaría General de Hacienda, Dirección General del Catastro.

8 Ministerio de Fomento: Estimación del Parque de Viviendas. Viviendas por Comunidades Autónomas y Provincias. Series 2001-2010. 
se localizaron bien en el medio rural, bien en núcleos de las franjas periurbanas. En 2010 el Catastro registraba la existencia de 1.664 .110 residencias, con una distribución territorial muy alejada de la correspondiente a la población. Mientras el conjunto del medio urbano, considerando como tal no sólo las ciudades (municipios mayores de diez mil habitantes) sino también los espacios periurbanos y las áreas de influencia ligados a ellas, concentraba en ese año el $65 \%$ de los residentes, la proporción de viviendas se reducía al 53\%. Una diferencia debida en parte al menor tamaño de las unidades familiares y a la importancia de las casas desocupadas en los núcleos rurales, pero también a la abundante presencia de viviendas utilizadas como segunda residencia. Entre 2001 y 2010 el parque inmobiliario castellano y leonés se incrementó en un 19,4\% según fuentes del Ministerio de Fomento (Fig.5), correspondiendo a Segovia $(25,1 \%)$ y Valladolid $(23,8 \%)$ los mayores porcentajes. Pero mientras el número de viviendas principales sólo creció un $15,4 \%$, el de secundarias lo hizo en el 25,7\% y en este aspecto fueron Ávila, León, Segovia y Zamora las más beneficiadas en términos relativos, concentrándose en tres provincias (Ávila, Burgos y León) cerca de la mitad. La disparidad entre ambas tendencias supuso un mayor peso de la residencia secundaria, pasando de representar el 39\% del total en 2001 al $41 \%$ al finalizar la década. Una década en la cual se consolidó la posición predominante que ya tenía Ávila desde años anteriores, pues si bien en León las cifras absolutas eran superiores (130.145 viviendas secundarias frente a 108.869), el parque inmobiliario abulense era mucho más moderno y se encontraba en mejor estado que el leonés ${ }^{9}$. De hecho, la práctica totalidad del aumento en la provincia durante esos años responde a la proliferación de urbanizaciones destinadas al tiempo de ocio, sin apenas variar el saldo final de moradas principales, cuya cantidad había ascendido hasta 2008 pero se redujo posteriormente. La evolución en Burgos muestra algunas coincidencias con la abulense, disponiendo de más de cien mil residencias secundarias caracterizadas en el $90 \%$ de los casos por su buen estado de conservación, pese a que a escala provincial su peso relativo es incluso inferior al promedio regional. Si no en cifras absolutas, sí en términos relativos tanto en Segovia como en Soria poseen asimismo una importancia destacada las viviendas secundarias, al ser la mitad de las existentes en ambas provincias. Junto a Ávila, son las tres provincias donde el aporte de visitantes procedentes de fuera de la Comunidad es mayor, superando el $88 \%$. El influjo de Madrid se extiende a todo este sector suroriental de Castilla y León, al igual que el del País Vasco en el norte de Burgos. También Zamora ha experimentado un auge en este sentido, gracias asimismo a que junto al mantenimiento de la casa en el pueblo de origen de los emigrados, muchos de ellos han adquirido una nueva, sumándose otros turistas de variada procedencia. En conjunto, el $72 \%$ de quienes visitan la provincia residen durante la mayor parte del año en otras CC.AA., y a pesar de que en términos comparativos con las otras provincias ya citadas los guarismos resultantes sean bajos, las consecuencias a escala interna son sin duda positivas, como indica el aumento en un $40 \%$ entre 2001 y 2010 del número de las viviendas no principales, el mayor registrado en toda la Región (Ministerio de Fomento, 2010) ${ }^{10}$.

9 El 93\% de las viviendas en Ávila se encontraban en buen estado y en León el 89\%, según el Censo de 2001. El mayor crecimiento del parque inmobiliario abulense conlleva que ambos porcentajes hayan tendido a distanciarse.

10 En 2008 Zamora fue la provincia con mayor número de edificaciones de nueva planta destinadas a viviendas unifamiliares, el 21\% de toda Castilla y León, cuando en 2004 el primer lugar lo ocupaba Segovia, con el 24\%. 


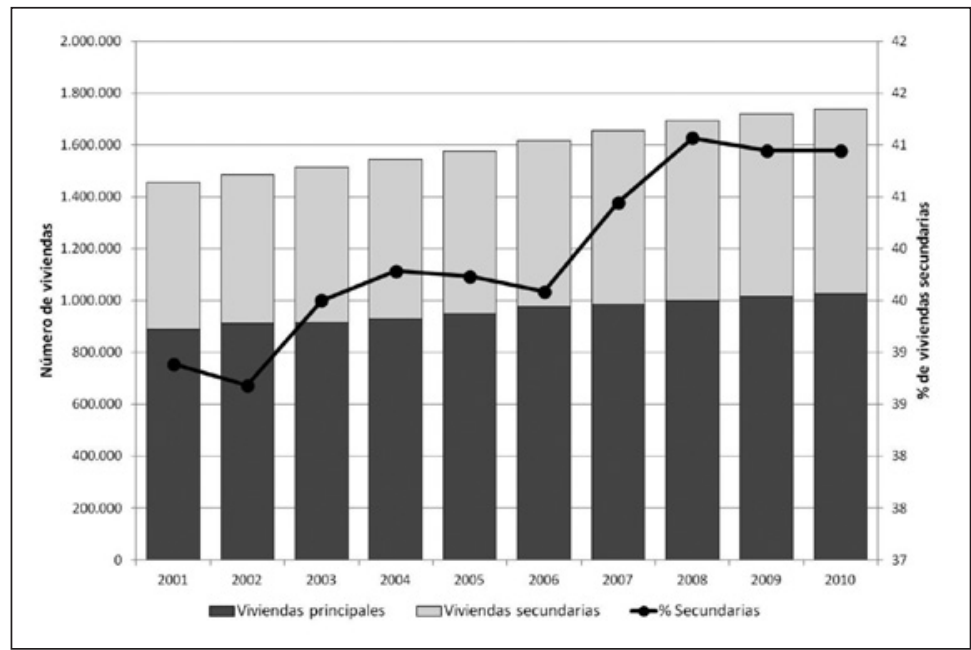

Fuente: Ministerio de Fomento: Estimación del Parque de Viviendas.

Con todo, el análisis de la información suministrada por la Estimación del Parque de Viviendas no permite diferenciar la escala municipal, debiendo recurrir directamente al Catastro Inmobiliario Urbano, cuyo problema radica en la no distinción del tipo de vivienda. Aun así, posibilita establecer una comparación entre el peso demográfico y el del parque inmobiliario, ayudando a vislumbrar la disponibilidad de alojamientos existentes en domicilios familiares y confirmando algunos de los aspectos ya señalados (Caballero, Delgado y Martínez, 2012). El grado de ocupación es uno de ellos, marcando importantes diferencias entre los medios urbano y rural y dentro de éste, el papel de los principales centros de servicios, donde además el tamaño medio de las familias es mayor. La consideración del total de viviendas o solamente de las ocupadas es otra variable fundamental, dado que el porcentaje de ellas cuyo estado impide la habitabilidad es directamente proporcional al vaciamiento demográfico padecido. Junto a las áreas de menor densidad de población, las favorecidas por la abundancia de nuevas urbanizaciones residenciales también presentan índices de ocupación muy bajos, al incrementar su parque inmobiliario con residencias secundarias de propietarios no empadronados. En el primer caso, la mayoría son núcleos muy reducidos que apenas reciben visitantes estacionales, mientras en el segundo la población flotante constituye una de las bases de su economía. De ahí que la información sobre residentes por vivienda ocupada resulte útil, pues tal ocupación supone una mayor probabilidad de recibir la visita temporal de familiares.

En Castilla y León la relación habitantes/vivienda es de 2,57, inferior al promedio nacional $(2,74)$, con máximos en Valladolid $(2,78)$, Burgos y Palencia $(2,68)$, no llegando a la media regional las restantes provincias ${ }^{11}$. Las causas son varias y van más allá de la escasa

11 Según relación establecida a partir de datos del Padrón Municipal de Habitantes y del Catastro Inmobiliario Urbano para 2010. El Ministerio de Fomento en su Encuesta de movilidad de las personas residentes en España 
densidad de población, incluyendo el elevado número de viviendas de nueva construcción desocupadas. Al finalizar 2010 el total de éstas en España era de 687.523, de las cuales 42.724 se localizan en la Comunidad, con un stock de 16,7 por mil habitantes que llegaba a 23,7 en Ávila y a 20,3 en Soria, cuando el promedio nacional era de 14,6 (Ministerio de Vivienda, 2011). De las ocupadas, el 24\% lo están por un único residente (19\% en España), alcanzando el $27 \%$ en Soria. Su perfil corresponde al de personas de edad avanzada que en el $76 \%$ de los casos superan los cincuenta años, frente al $66 \%$ de media nacional. Índices aún más extremos en el medio rural, reflejando la existencia del elevado número de viviendas infrautilizadas la mayor parte del año, pero aprovechadas en vacaciones y fines de semana por familiares de los residentes, añadiéndose así a las plazas de alojamiento vinculadas a residencias secundarias. El número de personas por vivienda es en general bajo en el medio rural, aumentando en consonancia con el peso demográfico del núcleo. Los municipios menores de dos mil habitantes registran un índice de 2,07, con mínimos en Zamora (1,75), la provincia de población más envejecida, mientras Valladolid posee por el contrario un grado de ocupación elevado y en gran medida independiente del tamaño del municipio. A escala regional el número de ocupantes por vivienda funcional da una imagen más favorable que el de densidad de población y refleja mejor el potencial de atracción de visitantes.

Junto al aprovechamiento de viviendas familiares o de conocidos, la residencia secundaria propia es, como ya se indicó, el segundo tipo de alojamiento elegido por los turistas. Su análisis a escala municipal se realiza mediante explotación de los datos del Censo de Viviendas de 2001, pero desde entonces ha aumentado tanto su número como su peso relativo en el parque inmobiliario, aunque la diferencia sea reducida (López y Módenes, 2004) ${ }^{12}$. Si según el Ministerio de Fomento en 2010 y a escala regional el $41 \%$ de las existentes respondía a tal definición, en 2001 eran el 39\%, suponiendo el 41\% de las localizadas en municipios rurales y el $27 \%$ en los urbanos. En general, la importancia relativa de las segundas residencias es algo mayor en los núcleos de menor tamaño, ya se trate del medio rural profundo o de centros de servicios de menor entidad, que en las franjas de la periferia urbana, pese al rápido proceso de construcción de este tipo de alojamientos desde los años ochenta. Cerca de la mitad de las existentes en 2001 (el 46\%) se localizaban en municipios menores de dos mil habitantes, a las cuales han de añadirse las ubicadas en centros de servicios, otro 17\%, justificando el asimismo elevado número de viajeros que optan por pasar sus días de asueto en viviendas propias ${ }^{13}$. El conjunto de municipios menores de diez mil habitantes, que en términos demográficos agrupa solamente el 35\% de la población regional, disponía en cambio del $41 \%$ de las residencias principales y el $62 \%$ de las secundarias. Las capitales mostraban

(Movilia 2006/2007) daba para 2006 índices algo inferiores: 2,54 habitantes por vivienda ocupada en Castilla y León frente a 2,70 en España, con máximos en Valladolid $(2,67)$, Burgos y Palencia $(2,63)$.

12 El Censo de Población y Vivienda de 2001 define como vivienda secundaria la no utilizada como vivienda principal o habitual y usada para otros fines de manera temporal, lo cual va más allá de la idea general de contabilizar únicamente las destinadas a vacaciones y ocio, incluyendo las ocupadas ocasionalmente por motivos laborales. Con todo, al haberse utilizado el Catastro como fuente inicial para su realización, los datos no difieren apenas de los suministrados por éste para el mismo año. Así, de las 1.455 .050 viviendas registradas en el Catastro en 2001 (889.197 principales y 565.853 no principales), el Censo confirmaba la existencia de 1.449 .415 (889.275 principales y 560.140 no principales).

13 No se contabilizan en este apartado los municipios que, siendo menores de dos mil habitantes, pertenecen a las franjas periurbanas o a las áreas de influencia urbana. 
un peso relativo muy bajo para este segundo tipo de viviendas, apenas una cuarta parte del total de su parque inmobiliario, incrementando su presencia al aumentar la distancia a la ciudad hasta un máximo correspondiente a las áreas de influencia más allá del periurbano colindante, donde eran el $46 \%$ del total. En los centros de servicios de primer orden, con una población de entre cinco mil y diez mil residentes, el porcentaje desciende ligeramente (44\%) debido a que el crecimiento o mantenimiento de su potencial demográfico se logró por la captación de familias que habitaban anteriormente en pueblos cercanos y trasladaron su residencia principal, ocurriendo lo contrario en ellos, ya que al perder población y con ella ocupación en viviendas principales la proliferación de residencias secundarias ha elevado considerablemente ese porcentaje. Y vuelve a aumentar su importancia en los pequeños centros y núcleos rurales, donde la mitad de las viviendas son secundarias.

Aunque la importancia de la segunda residencia en el medio rural es manifiesta, las cifras han de matizarse en virtud de otros factores. En primer lugar, la proporción de viviendas vacías es algo superior en los pequeños municipios, un 12,2\% cuando la media regional es del $11,7 \%$, llegando al 17,0\% en los centros de servicios de entidad reducida, en las áreas de menor densidad de población. El medio rural registra, igualmente, el mayor porcentaje de las catalogadas como en estado ruinoso, malo o deficiente, un 11,1\%, frente al 7,9\% de las capitales o magnitudes aún inferiores en las periferias urbanas, allí donde los procesos de crecimiento han sido más rápidos y recientes, como el periurbano $(4,4 \%)$ o sus áreas de influencia $(6,1 \%)$. En los centros de servicios más dinámicos el estado de los edificios es relativamente bueno, siendo entre un 6 y $8 \%$ los que presentan deterioro en mayor o menor grado. La distribución provincial de la residencia secundaria rural muestra nuevamente la capacidad de atracción de Ávila, con el $20 \%$ de las existentes en toda la Comunidad y donde, además, la relación entre éstas y las principales es claramente favorable a las primeras (61\%). Tras ella, Burgos concentra el $16 \%$, con un peso relativo sobre el total de viviendas asimismo elevado (57\%). En ambos casos la diferencia con respecto a las restantes provincias es muy marcada, así como la existente en relación al número de residencias principales, que guarda una vinculación más directa con la población empadronada, el modelo de poblamiento y el tamaño medio de la unidad familiar, generando una menor ocupación allí donde el envejecimiento es intenso y la ocupación del territorio más dispersa. Sólo en los municipios rurales de Segovia y Soria, por el peso de la población flotante, la proporción de residencias secundarias supera como en Ávila y Burgos el 50\% del parque inmobiliario.

La conjunción de todas las fuentes utilizadas permite apreciar la importancia de la residencia secundaria en las áreas de mayor atracción turística, entre las que destaca sobremanera la franja meridional abulense y segoviana, extendiéndose a municipios sorianos, así como en las Merindades del norte burgalés, donde igualan o superan en número a las principales. En 988 municipios rurales de Castilla y León se daba esta situación, sumando ya en 2001 un total de 202.282 viviendas secundarias, constituyendo en un centenar de ellos como mínimo el 75\% de las censadas. Destacan en cifras absolutas los abulenses de Navaluenga, El Tiemblo, La Adrada, Sotillo de la Adrada, Arenas de San Pedro, Navas del Marqués o Candeleda; los segovianos de El Espinar, Riaza, San Ildefonso y Ayllón; los sorianos de Arcos del Jalón, Almazán, San Esteban de Gormaz y Burgo de Osma; u otros más alejados del borde montañoso meridional, como Cuéllar o Cantalejo en la Tierra de Pinares Segoviana. En Burgos sobresalen en este aspecto Medina de Pomar, Villarcayo, Valle de Tobalina, Valle de Mena 
o Espinosa de los Monteros y, en el interior, Briviesca. Carrión de los Condes y Aguilar de Campoo destacan en el caso de Palencia, Toro en Zamora, Tordesillas en Valladolid o Peñaranda de Bracamonte en Zamora, por citar algunos de los más importantes. De las 347.915 residencias secundarias ubicadas en 2.069 municipios del medio rural, la mitad se concentraban en tan sólo 230 y una cuarta parte en medio centenar. A la mayor cifra comparativa de viviendas en relación a sus habitantes en pequeños municipios y centros de servicios se une la dispar ubicación de las residencias secundarias, incrementando la cuantía de la población flotante que pueden captar estos núcleos. Cuantía que a escala regional y provincial se ha podido conocer a través de los datos sobre turismo interior, aunque referida a visitas, pero no a población exacta, pues al incluir todo tipo de desplazamientos (fines de semana, puentes, vacaciones) un mismo visitante figura en repetidas ocasiones. Suponiendo que los viajes realizados por motivos vacacionales durante el verano fueran únicos, Castilla y León recibiría entre 1,3 y 1,5 millones de visitantes, procedentes el $15 \%$ de la propia Comunidad. No obstante la aproximación no sólo resulta arriesgada, sino que tampoco permite diferenciar el lugar exacto de los destinos (FAMILITUR, datos medios de 2008 a 2010). Se ha de recurrir nuevamente, por tanto, a la información proporcionada por el Censo de Población de 2001 relativa al concepto de población vinculada o, para obtener datos más actuales, a la Encuesta de Infraestructuras y Equipamientos Locales del Ministerio de Hacienda y Administraciones Públicas. Esta última ratifica cómo en los meses señalados la población de los núcleos rurales experimenta una revitalización significativa, pero también en menor medida a lo largo de todo el año gracias a las visitas de fin de semana, llegando a multiplicar varias veces la cifra de empadronados en las fechas de mayor afluencia, como se analizará a continuación.

\section{LA DESIGUAL INCIDENCIA ESPACIAL DE LOS MÁXIMOS POBLACIONALES}

La población vinculada considera tres categorías ligadas a la movilidad espacial de la población: el trabajo, la realización de estudios y la disponibilidad de una residencia secundaria, siendo esta tercera la que ejerce una mayor presión en la carga demográfica de los municipios rurales como se ha comprobado en el análisis previo de la distribución espacial de este tipo de viviendas. Se descartan en cambio otras opciones, como el turismo o las vacaciones de quienes no disponen de una residencia secundaria, si bien ambas ya han sido consideradas a través de las fuentes de información correspondientes ${ }^{14}$. La carga adicional que supone la población vinculada deriva de la utilización de servicios e infraestructuras, necesidad de instalaciones, generación de residuos, consumo de suministros o impacto medioambiental, entre otros aspectos y, lógicamente, no es la misma tratándose de estudiantes, trabajadores o visitantes alojados en una segunda residencia. En sentido opuesto, se trata de una población flotante generadora de rentas y en muchos casos supone la base de la economía local (Vinuesa, 2005). El primer paso a seguir consiste por tanto en cuantificar esa población y los motivos de su presencia, diferenciando asimismo los ámbitos territoriales de procedencia desde la escala regional a la provincial y municipal. Cuanto más se concrete la

14 Los turistas que no pernoctan en vivienda propia o familiar eran solamente el $26,1 \%$ del total, por lo que el restante $73,9 \%$ sí se incluye en el cómputo de la población vinculada por disponer de una residencia secundaria. 
escala mayor será la cuantía de la población vinculada, al considerar desplazamientos solamente interprovinciales o también intermunicipales dentro de una misma provincia.

En el conjunto de la Comunidad la cifra total de población vinculada es muy elevada, pues ya a finales de 2001 alcanzaba cerca del millón de personas, un 39\% de la población de derecho censada. Esa cifra incluye tanto a quienes residiendo fuera de Castilla y León tienen aquí su segunda residencia, trabajan o estudian, como a los castellanos y leoneses que lo hacen en un municipio distinto al de residencia habitual. La carga real a escala regional -no la suma de las cargas municipales o provinciales- se obtiene de restar de ese total el segundo grupo, lo cual reducía en ese año la cuantía final a 434.859 personas que, aunque residiendo fuera de la Región, mantenían estrechos vínculos con ella y suponían el 18\% de los empadronados. Un índice ya utilizado para cuantificar la importancia de esta población es la tasa de vinculación o cociente entre la población total (residente más vinculada) y la residente, expresado en forma de porcentaje (el 100\% indicaría la ausencia de población vinculada, el $200 \%$ la igualdad entre ambas poblaciones, etc.). A escala de la Comunidad Autónoma, la tasa de vinculación en la fecha censal sería por tanto del 117,7\%, mientras que a una escala municipal ascendería al 139,2\%. Aplicando esta segunda opción, que en realidad cuantifica mejor las necesidades y beneficios asociados a la población flotante de un territorio, Castilla y León surge como la segunda comunidad autónoma en importancia, solamente superada por Cantabria (140,7\%), sobre un promedio nacional del 128,5\% (Alberich, 2009). Las aportaciones más destacadas proceden de Madrid, que concentra más de la mitad de la población vinculada llegada de fuera (52\%), seguida del País Vasco (22\%), ratificando las conclusiones obtenidas en el estudio de localización de las residencias secundarias. En un escalón más alejado se encuentra Asturias (7\%), mientras los porcentajes descienden en torno al $2 \%$ en las restantes CC.AA. que guardan vecindad con Castilla y León. Destaca el caso de Cataluña, aportando el $5 \%$ de la población flotante, debido no sólo al turismo como tal, sino sobre todo a la elevada presencia en ella de emigrantes que mantienen lazos familiares con su municipio de origen. De ellos, con excepción de los residentes en la propia Comunidad, la inmensa mayoría $(92,6 \%)$ tienen su vínculo de conexión en la existencia de una residencia secundaria, si bien ésta no ha de ser necesariamente de su propiedad, considerando también como tales las viviendas en alquiler o cedidas gratuitamente, lo que incluye en el cómputo las viviendas de familiares, asimismo analizadas en párrafos precedentes. Esto la asemeja a la mayoría de las CC.AA., con las salvedades de Cataluña, Madrid, Navarra y el País Vasco, donde el vínculo principal es de carácter laboral. Desde el punto de vista de la procedencia de los residentes temporales, solamente entre los extremeños la disponibilidad de residencia no supone el motivo principal, siendo éste la realización de estudios, si bien ambos se hallan casi a la par (38\%). También en Galicia, Cantabria o La Rioja los desplazamientos temporales a Castilla y León para cursar estudios poseen una cierta relevancia (15-20\% del total de vinculados), mientras que son numerosos los castellanos y leoneses que han de vivir en municipios ajenos al de residencia por motivos laborales, sumando el $40 \%$ de toda esa población itinerante.

A escala provincial el cómputo es otro, al no considerar los desplazamientos intermunicipales dentro de cada provincia, sino solamente los interprovinciales y los llegados de otras CC.AA. La diferencia no es baladí, pues asciende a 432.709 personas, lo cual demuestra la importancia de los viajes de corto radio -el $45 \%$ del total-, con independencia de su motivación. El 79\% de quienes han de vivir durante parte del año en un municipio diferente al de su 
residencia habitual por motivos laborales no salen para ello de su propia provincia (181.099 personas), una proporción que tiende a elevarse debido al proceso de periurbanización en torno a las principales ciudades de la Comunidad, pues al aumentar el radio de las áreas de influencia urbana lo hace asimismo el número de personas que permanecen durante la semana laboral allí donde trabajan, pese a encontrarse domiciliados en otro municipio. En las capitales se suman así a los problemas derivados de los desplazamientos de carácter pendular o diarios entre residencia y trabajo estos segundos, incidiendo en una mayor intensidad del tráfico en horas punta y consiguientemente en la necesidad de aumentar las inversiones en las vías de acceso y aparcamientos, entre otros ${ }^{15}$. También entre los estudiantes son elevados los movimientos intraprovinciales, afectando al 56\% del total de quienes los realizan, si bien en términos absolutos se limitaban a 46.776 personas. Por el contrario, cuando la causa es la existencia de una segunda residencia y la vinculación responde a otras razones (ocio, visitas familiares), la escala provincial solamente justifica el 31\% de esta población flotante, pese a que en cifras absolutas se superen los otros motivos (204.834 personas). Pero la inmensa mayoría mantienen esa segunda residencia en una provincia diferente, lo cual responde en parte a la dispar capacidad de captación de inmigrantes que mantuvieron las ciudades de Castilla y León durante la etapa de expansión de los años cincuenta a setenta, pero sobre todo a la emigración extrarregional, al conjunto de castellanos y leoneses que viven y trabajan fuera de la Comunidad. En cualquier caso, la importancia relativa de los motivos de vinculación es similar a la ya analizada a escala regional, predominando la disponibilidad de residencias secundarias sobre el trabajo y los estudios.

Desde el punto de vista de la mayor o menor presencia de población vinculada, la disponibilidad de residencia secundaria es sin duda el motivo más destacado y por tanto en él centraremos el análisis a escala municipal. Lo primero que llama la atención, confirmando otras aproximaciones al tema, es el peso de la población procedente de fuera de la Comunidad Autónoma, el $62 \%$ de todos los que disponen de una segunda vivienda, proporción mucho más elevada en Ávila (90\%) y Segovia (82\%) por causas ya explicadas (la influencia de Madrid). Solamente en Valladolid este porcentaje es reducido (26\%), algo mayor en Salamanca (44\%) y superior al 50\% en todas las demás provincias. De las 402.670 personas que acudían desde otras CC.AA. algo más de un tercio (137.618) son emigrantes nacidos en Castilla y León, la mayoría afincados en Madrid y el País Vasco. Comparando esta cifra con el total de nacidos en la Región y que según el Censo de 2001 vivían en otras comunidades el porcentaje de aquellos que conservan una estrecha relación con su lugar de origen a través de la vinculación por vivienda secundaria es del $12 \%$ y suponen una quinta parte de esta población flotante. Nuevamente y por obvios motivos de proximidad son los ahora residentes en Madrid y el País Vasco quienes muestran una presencia más destacada, pues casi el 16\% de ellos mantienen este tipo de enraizamiento, disminuyendo a aproximadamente un $6 \%$ entre los residentes en otras regiones cercanas y, lógicamente, cayendo a mínimos en torno al 3\% en las más alejadas. Las CC.AA. de residencia de la población vinculada varían ligeramente según la provincia beneficiada por estos flujos, pese al predominio de las ya indicadas. Los madrileños suponen más del $90 \%$ en Ávila y Segovia, mientras en las demás provincias los

15 Este tipo de desplazamientos también se da en sentido contrario, afectando a empresarios y trabajadores agrarios con residencia en la ciudad. 
puntos de origen muestran una mayor diversificación, aunque la influencia de la capital de España sea manifiesta en todas ellas. La relación con el País Vasco es indudable en Burgos y también presenta un papel destacado en Palencia -donde se atrae asimismo a población cántabra- y, en menor medida, en Valladolid y Zamora. León recibe en cambio más población flotante proveniente de Asturias, mientras en Soria, aunque sean mayoritarios los madrileños, destaca la presencia de aragoneses y catalanes. Al igual que en otros aspectos, la proximidad geográfica explica la mayor parte de estas diferencias, sin olvidar que el enorme peso demográfico de Madrid empaña en términos relativos la presencia de otros visitantes. No debe olvidarse que Castilla y León es el destino prioritario de los viajeros procedentes de Madrid, ocupando asimismo el primer puesto en los viajes extra regionales de asturianos, cántabros y riojanos y el segundo en el caso de los gallegos y vascos (FAMILITUR, 2010).

Las cifras de población vinculada por disponibilidad de una segunda residencia eran ya por tanto muy elevadas en 2001 y teniendo en cuenta que su evolución coincide a grandes rasgos con las del turismo no reglado, éstas sí cuantificadas para fechas más recientes, las 651.496 personas integrantes de este colectivo flotante habrían aumentado como mínimo al finalizar la década en torno a un $24 \%$, superando las 800.000 , y ello si se consideran solamente los desplazamientos derivados del aprovechamiento del tiempo de ocio. No obstante, la inexactitud de las respuestas obtenidas en las encuestas de FAMILITUR hace sospechar que gran parte de los desplazamientos encasillados en el apartado de «visitas familiares» responde asimismo al ocio, lo que casi duplicaría la cifra real de población añadida en períodos vacacionales y, sobre todo, durante el verano, llegando a 1.544 .248 personas ${ }^{16}$. Ahora bien, es preciso diferenciar espacialmente el destino de esta población, utilizando para ello una escala municipal que permita revelar el impacto demográfico de la tenencia de vivienda en el ámbito rural por parte de los residentes en ciudades de la Comunidad o de fuera de ella. Para ello ha de recurrirse nuevamente al Censo de 2001, desarrollando en los casos posibles las aproximaciones a la situación en 2010 según tendencias conocidas. Un primer problema que plantea este desglose es la imposibilidad de realizarlo municipio a municipio en todos los existentes en Castilla y León, debiendo limitar el cálculo a grupos definidos por el número de residentes ${ }^{17}$. No es óbice para obtener las cifras correspondientes al conjunto del mundo rural a escala provincial, pero al utilizar como único criterio de delimitación la población se incluyen municipios menores de diez mil habitantes pertenecientes a las franjas periurbanas y áreas de influencia urbana, un error reducido en términos relativos que de acuerdo a otros datos incrementa las cifras ligeramente ${ }^{18}$.

16 En 2001 el total de viajes realizados por españoles con destino en Castilla y León fue de 14.051 .460 y de 17.433.260 en 2010, lo cual supone un incremento del 24,1\%. Para alcanzar la cifra del texto se ha extrapolado la población vinculada del Censo de 2001 a 2010 según la tendencia indicada (808.507 personas) y añadido una «población vinculada enmascarada», que aunque ausente del recuento censal sí aparece en FAMILITUR como visitante asidua a familiares residentes en Castilla y León y procedente de la misma o de otras CC.AA. (735.741 personas).

17 En efecto, el secreto estadístico impide recabar datos concretos en aquellos municipios que, por su reducida entidad, darían como resultado de la consulta información de carácter personal o familiar. Y así sucede en el caso de la vinculación de personas según los motivos que la relacionan con un segundo municipio, la disponibilidad de residencia secundaria.

18 Considerando, por ejemplo, las residencias secundarias, en 2001 el 7,3\% de todas las ubicadas en municipios menores de 10.000 habitantes se localizaban en espacios periurbanos o áreas de influencia urbana. El error 
Medio millón de habitantes se sumaban ya en 2001 a la población rural empadronada y la inmensa mayoría lo hacía en municipios de reducida entidad, con menos de dos mil residentes, aspecto destacable sobre todo en la provincia de Zamora, una de las más despobladas. Incluso en los territorios más urbanizados, casos de León, Salamanca y Valladolid, la proporción de población vinculada al mundo rural por segunda residencia era muy cercana o superaba ligeramente la mitad del total en estos enclaves. La numerosa presencia de viviendas pertenecientes a madrileños en Ávila y Segovia o a vascos en el norte de Burgos, con una mayor concentración espacial en núcleos de destacado atractivo turístico, explica que en las tres provincias se alcance o supere el $20 \%$ del total de población vinculada en municipios con más de 5.000 residentes. Un fenómeno que dista mucho de ser novedoso, pues ya ejercía un importante influjo en el medio rural desde los años ochenta, consecuencia en parte del éxodo padecido en décadas anteriores y causa del retorno temporal de las familias formadas por los antiguos emigrantes. En efecto, en 1981 la población de derecho era ya insignificante en relación a la población de hecho a partir de la primavera y, sobre todo, durante el verano. A los visitantes estivales se sumaban además habitantes que residían prácticamente todo el año, salvo en los meses más duros del invierno, aunque siguieran empadronados en sus núcleos de origen. Atendiendo, como se ha hecho en este análisis, a la disponibilidad de residencias secundarias, en 1981 los municipios menores de dos mil habitantes pertenecientes a las provincias de Ávila, Burgos, Segovia y Soria eran los más beneficiados por estos aportes. Aplicando las tendencias expuestas en el incremento del turismo interior y la proporción de población vinculada al medio rural según el Censo de 2001 (73,9\%), en 2010 la cifra total de población añadida durante el periodo estival sería en el total de estos municipios de 1.141.200 personas, lo que supone un incremento del 126\% sobre sus residentes empadronados, 898.665 si eliminamos del cómputo los enclavados en franjas periurbanas.

Los últimos datos ofrecidos por la Encuesta de Infraestructuras y Equipamientos Locales del Ministerio de Hacienda y Administraciones Públicas, referentes al año 2010, respaldan tanto los ya analizados procedentes de las fuentes sobre turismo interior como de la extrapolación de sus tendencias a los suministrados por el Censo de Población y Viviendas del INE. La encuesta incluye entre sus variables la población estacional máxima, definida como una «cifra estimada ponderadamente a partir de las evoluciones demográficas periódicas (veranos y fines de semana) observadas en los últimos años» que incluye «el total de la población residente habitual más la ocasional» ${ }^{19}$. La población residente habitual es la empadronada y por tanto, restada ésta de la estacional máxima, proporciona la cuantía de la población flotante u ocasional a escala municipal o para entidades de población concretas. En el conjunto de la Comunidad Autónoma esta carga demográfica añadida supone, en el ámbito rural, un incremento del $131 \%$ de sus habitantes habituales, añadiendo a los 898.665 empadronados en el año 2010 otros 1.181.128, cifra ligeramente superior a la obtenida en la aproximación anterior (Tabla 1). En términos relativos son precisamente los municipios menos poblados quienes se ven más beneficiados por dicho aporte, llegando a triplicar e incluso cuadruplicar en época estival el número de sus habitantes. Todos los grupos analizados reciben al menos

es mayor en las provincias con periurbanos ya ampliamente desarrollados en 2001, como sucede en Salamanca y Valladolid e insignificante donde éste apenas existía (Ávila, Palencia, Soria y Zamora).

19 Encuesta de Infraestructuras y Equipamientos Locales. Manual de instrucciones, pag.14. Los datos desglosados por municipios y entidades de población se encuentran en la tabla denominada «Núcleos Encuestados 1». 
más visitantes que vecinos afincados oficialmente, destacando, independientemente de su entidad, los caracterizados además de por su atractivo turístico, por el desarrollo de actividades agroindustriales basadas en el aprovechamiento intensivo de su potencial endógeno, justificante a su vez del peso demográfico. La mayoría de ellos pertenecen a la provincia de Ávila y se localizan en el Valle del Tiétar (La Adrada, Arenas de San Pedro, Candeleda, Piedralaves y Sotillo de la Adrada, como núcleos más importantes) y del Alberche (El Barraco, Burgohondo, Cebreros, El Hoyo de Pinares, Navaluenga, Las Navas del Marqués y El Tiemblo), con ejemplos más puntuales en Segovia, tanto en la cercanía a la Sierra del Guadarrama (El Espinar) y al Macizo de Ayllón (Riaza), como en la campiña (Coca), en el norte burgalés (Espinosa de los Monteros y Villarcayo), León (Valderas y Valencia de Don Juan) o Soria (San Esteban de Gormaz), por citar algunos de los más significativos.

Tabla 1

POBLACIÓN HABITUAL Y OCASIONAL EN MUNICIPIOS RURALES (2010)

\begin{tabular}{|c|c|c|c|c|c|}
\hline \multirow{2}{*}{$\begin{array}{l}\text { Tamaño del municipio } \\
\left.\text { ( } \mathrm{N}^{\circ} \text { de residentes }\right)\end{array}$} & \multirow{2}{*}{$\begin{array}{l}\text { Número de } \\
\text { municipios } \\
\text { (1) }\end{array}$} & \multicolumn{4}{|c|}{ Población } \\
\hline & & $\begin{array}{l}\text { Residente } \\
\text { (A) }\end{array}$ & $\begin{array}{l}\text { Ocasional } \\
\text { (B) }\end{array}$ & $\begin{array}{l}\text { Máxima } \\
(\mathrm{A}+\mathrm{B})\end{array}$ & $\% \mathrm{~B} / \mathrm{A}$ \\
\hline Menos de 50 & 197 & 6.905 & 21.549 & 28.454 & 312,1 \\
\hline de 50 a 99 & 359 & 26.649 & 54.241 & 80.890 & 203,5 \\
\hline de 100 a 199 & 536 & 77.780 & 126.314 & 204.094 & 162,4 \\
\hline de 200 a 299 & 291 & 70.765 & 104.207 & 174.972 & 147,3 \\
\hline de 300 a 399 & 169 & 58.742 & 78.048 & 136.790 & 132,9 \\
\hline de 400 a 499 & 111 & 49.958 & 69.578 & 119.536 & 139,3 \\
\hline de 500 a 599 & 90 & 49.269 & 62.619 & 111.888 & 127,1 \\
\hline de 600 a 699 & 46 & 29.589 & 40.346 & 69.935 & 136,4 \\
\hline de 700 a 799 & 33 & 24.666 & 26.674 & 51.340 & 108,1 \\
\hline de 800 a 899 & 30 & 25.497 & 37.084 & 62.581 & 145,4 \\
\hline de 900 a 999 & 32 & 30.428 & 33.125 & 63.553 & 108,9 \\
\hline de 1.000 a 1.999 & 99 & 132.231 & 158.250 & 290.481 & 119,7 \\
\hline de 2.000 a 4.999 & 58 & 171.179 & 221.474 & 392.653 & 129,4 \\
\hline de 5.000 a 9.999 & 21 & 145.007 & 147.619 & 292.626 & 101,8 \\
\hline Total & 2.072 & 898.665 & 1.181 .128 & 2.079 .793 & 131,4 \\
\hline
\end{tabular}

Fuente: Elaboración propia a partir de Ministerio de Hacienda y Administraciones Públicas: Encuesta de Infraestructuras y Equipamientos Locales 2010.

(1) No se incluyen municipios menores de diez mil residentes localizados en franjas periurbanas).

El mapa así elaborado (Fig. 6) perfila, por tanto, como principal área de atracción de población ocasional, en términos absolutos, las serranías abulenses y segovianas, alcanzando el influjo de los visitantes procedentes mayoritariamente de Madrid hasta el oeste y noroeste soriano. Destacan asimismo las Merindades del norte de Burgos, gracias al aporte vasco y, en menor medida, el norte leonés y palentino, por la llegada de población asturiana y cántabra, o los municipios del noroeste zamorano. En general, los datos obtenidos coinciden con las 


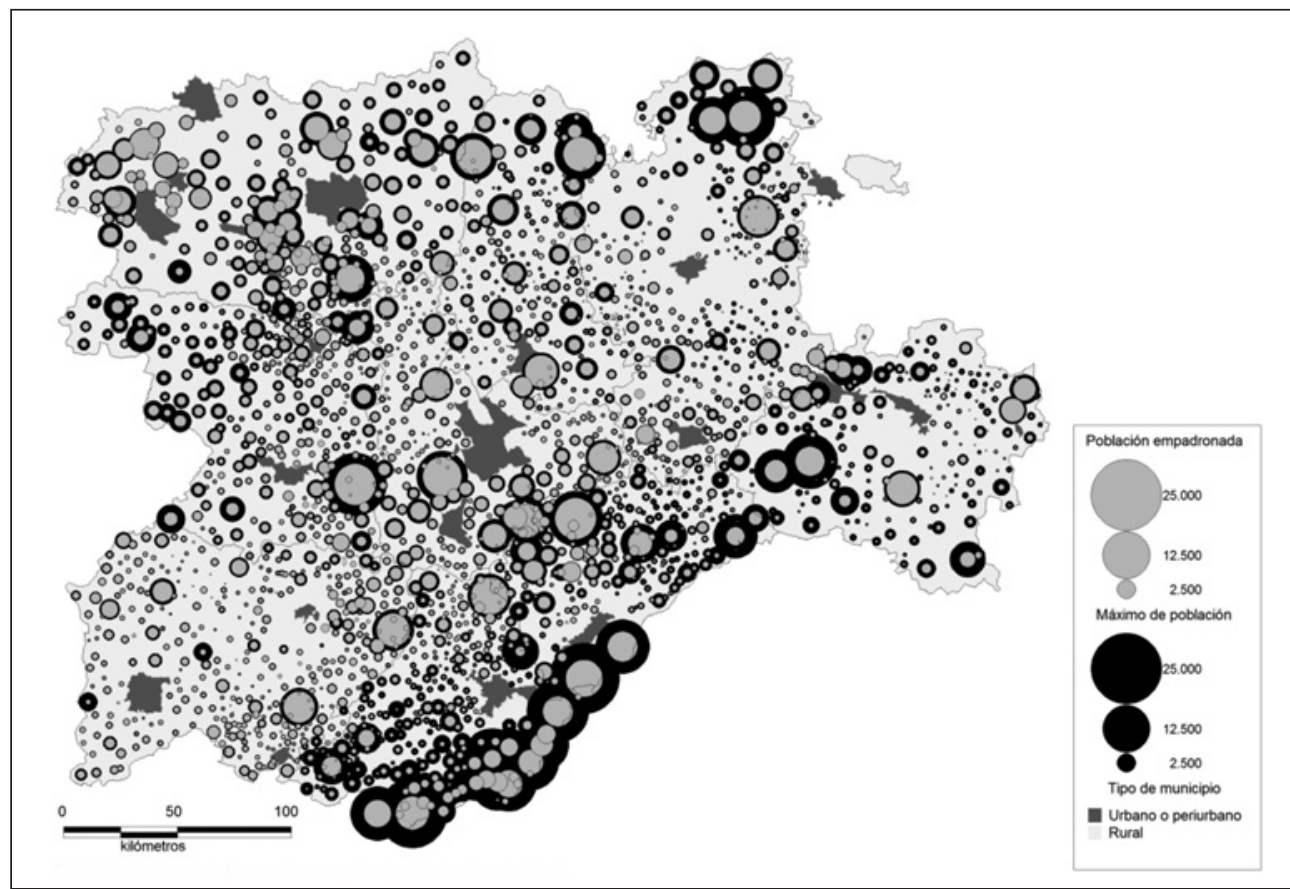

Fuente: Elaboración propia a partir de Ministerio de Hacienda y Administraciones Públicas: Encuesta de Infraestructuras y Equipamientos Locales 2010.

informaciones recogidas de las fuentes anteriores, derivadas del estudio del turismo interior, la disponibilidad de vivienda propia o familiar y la población vinculada registrada en el Censo de 2001, mostrando una pequeña ventaja para los municipios con menor número de residentes en la captación de población ocasional. Por debajo de los 600 habitantes empadronados la población ocasional supone el $152 \%$ de la habitual, reduciéndose al $118 \%$ al superar esa cifra. Pero más allá de la cuantificación del fenómeno a escala municipal, es en los núcleos de población concretos donde se percibe realmente el impacto de esta población flotante y, sobre todo, en los que han padecido con mayor virulencia el vaciamiento demográfico. El análisis del Nomenclátor permite una mejor definición del poblamiento rural al incluir núcleos que, pese a haberse clasificado como urbanos por pertenecer a municipios con más de diez mil residentes, no poseen individualmente tal entidad. Exceptuando como en el caso anterior las franjas periurbanas, la población rural asciende así cuantificada a 922.082 habitantes repartidos en 5.145 núcleos y aumenta un 129\% durante el máximo estacional. Cerca del $60 \%$ de los pueblos duplican en esas fechas, como mínimo, su población habitual. Los incrementos son mayores en los de menor tamaño, pues el envejecimiento extremo que padecen implica el predominio de individuos aislados o parejas mayores, por lo que las visitas familiares suponen triplicar la población residente e incluso a quintuplicarla en el caso de 671 núcleos, el $90 \%$ de ellos menores de cien habitantes. Los destinos más beneficiados por 
Tabla 2

POBLACIÓN HABITUAL Y OCASIONAL EN NÚCLEOS RURALES (2010)

\begin{tabular}{|c|c|c|c|c|c|}
\hline \multirow{2}{*}{$\begin{array}{l}\text { Tamaño del núcleo } \\
\left.\text { ( } N^{\circ} \text { de residentes }\right)\end{array}$} & \multirow{2}{*}{$\begin{array}{l}\text { Número de } \\
\text { núcleos } \\
\text { (1) }\end{array}$} & \multicolumn{4}{|c|}{ Población } \\
\hline & & $\begin{array}{c}\text { Residente } \\
(\mathrm{A})\end{array}$ & $\begin{array}{l}\text { Ocasional } \\
\text { (B) }\end{array}$ & $\begin{array}{c}\text { Máxima } \\
(\mathrm{A}+\mathrm{B})\end{array}$ & $\% \mathrm{~B} / \mathrm{A}$ \\
\hline Menos de 50 & 2.369 & 54.113 & 144.437 & 198.550 & 266,9 \\
\hline de 50 a 99 & 980 & 70.015 & 115.273 & 185.288 & 164,6 \\
\hline de 100 a 199 & 843 & 118.686 & 161.994 & 280.680 & 136,5 \\
\hline de 200 a 299 & 362 & 87.300 & 104.664 & 191.964 & 119,9 \\
\hline de 300 a 399 & 178 & 61.904 & 70.853 & 132.757 & 114,5 \\
\hline de 400 a 499 & 91 & 41.241 & 42.642 & 83.883 & 103,4 \\
\hline de 500 a 599 & 74 & 40.184 & 47.225 & 87.409 & 117,5 \\
\hline de 600 a 699 & 35 & 22.577 & 26.066 & 48.643 & 115,5 \\
\hline de 700 a 799 & 24 & 17.817 & 14.593 & 32.410 & 81,9 \\
\hline de 800 a 899 & 22 & 18.604 & 25.816 & 44.420 & 138,8 \\
\hline de 900 a 999 & 30 & 28.618 & 33.474 & 62.092 & 117,0 \\
\hline de 1.000 a 1.999 & 71 & 98.054 & 109.115 & 207.169 & 111,3 \\
\hline de 2.000 a 4.999 & 48 & 142.763 & 194.655 & 337.418 & 136,3 \\
\hline de 5.000 a 9.999 & 18 & 120.206 & 99.885 & 220.091 & 83,1 \\
\hline Total & 5.145 & 922.082 & 1.190 .692 & 2.112 .774 & 129,1 \\
\hline
\end{tabular}

Fuente: Elaboración propia a partir Ministerio de Hacienda y Administraciones Públicas: Encuesta de Infraestructuras y Equipamientos Locales 2010.

(1) No se incluyen núcleos menores de diez mil residentes localizados en franjas periurbanas).

estos aportes demográficos son sin embargo, en términos absolutos, algunos de los principales centros de servicios. De los 66 mayores de dos mil habitantes que cumplen tales funciones solamente en 25 la población ocasional supera a la empadronada y el total de habitantes únicamente se triplica en 15 de ellos, coincidiendo los ubicados en las áreas ya mencionadas.

Las comarcas abulenses de los Valles del Tiétar y del Alberche, con una población empadronada de 61.943 personas en 2010, alcanzan los 269.275 habitantes durante el verano, es decir, experimentan un incremento del $335 \%$. Éste se reduce hacia el este, en la franja meridional segoviana y la Sierra de Guadarrama, donde el crecimiento es del $220 \%$ (de 24.753 a 79.322). En cuanto a Las Merindades burgalesas el aumento es del 172\% en esa estación, de 26.125 a 71.016 habitantes. Aunque con una distribución más dispersa, otros centros de servicios llegan asimismo a triplicar sus residentes (Valderas en León y Riaza en Segovia) o a duplicarlos holgadamente (Burgo de Osma y San Esteban de Gormaz, en Soria), siendo también expresivos algunos núcleos de menor entidad en el norte palentino (Barruelo de Santullán), las riberas leonesas (Valencia de Don Juan) o el noroeste zamorano (Puebla de Sanabria o Galende, entre otros). En definitiva, los centros de tamaño intermedio en el medio rural con mayores densidades de población, que en Castilla y León tienen entre 2.000 y 5.000 habitantes, o aquéllos mucho menos poblados que, sin alcanzar el millar de residentes, al localizarse en áreas de escasa densidad han de cumplir funciones similares. 


\section{CONCLUSIONES}

El ámbito rural de Castilla y León se ha caracterizado desde hace más de medio siglo por una continua merma de su población, afectada primero por el intenso vaciamiento derivado del éxodo hacia las ciudades de dentro y fuera de la Comunidad y, actualmente, por una dinámica natural negativa, que responde al elevado envejecimiento de sus residentes. La imagen dada por las meras cifras de las estadísticas del Padrón Municipal de Habitantes es en consecuencia muy negativa, pero enmascara una realidad que ha de ser también considerada. Con independencia del número de vecinos afincados en los pequeños pueblos de su mapa municipal, que no puede ser calificado sino como extremadamente fragmentado, existe otro aporte demográfico no contabilizado: una población ocasional que cada verano y también en muchos fines de semana acude allí donde todavía habitan sus familiares, conservan su antigua residencia o han edificado una nueva. A ellos se suman además los visitantes de otras CC.AA., procedentes de Madrid en el caso del borde serrano meridional abulense y segoviano, del País Vasco tratándose de las Merindades burgalesas, o de asturianos y cántabros en las riberas leonesas y palentinas. Los datos aportados por la Encuesta de Infraestructuras y Equipamientos Locales revelan que durante el periodo estival su población llega a duplicarse holgadamente, confirmando las informaciones deducidas de otras fuentes indirectas, hecho muy a tener en cuenta por su efecto económico dinamizador que, en un elevado número de casos, es lo que posibilita no solamente el sostén a lo largo del resto del año de los negocios todavía presentes en estos pequeños pueblos, sino la proliferación de otros de nuevo cuño. Incremento poblacional que, aunque es cierto implica beneficios económicos, también exige el mantenimiento, cuando no la creación, de infraestructuras y servicios para atenderlo. Una realidad que ha de ser sin duda tenida en cuenta a la hora de delimitar un nuevo mapa de la Administración Local en ésta y otras CC.AA. En definitiva, la toma en consideración no sólo del número de residentes, sino asimismo de la cuantía de la mencionada población flotante, se hace necesaria antes de acometer cualquier reforma del modelo de ordenación y gobierno del territorio que implique una redistribución de la localización de equipamientos y centros prestadores de servicios.

\section{BIBLIOGRAFÍA}

ALARIO TRIGUEROS, M. (2005): «El Turismo rural: pluriactividad y creación de empleos para grupos de difícil inserción» en La situación de los nuevos yacimientos de empleo en Castilla y León (Delgado Urrecho, J.M. y Caballero Fernández-Rufete, P., Coord.). Valladolid, Edit. CES de Castilla y León, 361-344.

ALARIO TRIGUEROS, M. (2006): «Políticas públicas de desarrollo rural en Castilla y León, ¿sostenibilidad consciente o falta de opciones?: LEADER II». Boletín de la Asociación de Geógrafos Españoles, nº41, 267-293.

ALARIO, M. y MORALES, E. (2012): «Nuevos pobladores, nuevas, funciones, nuevos paisajes: emprendedoras y turismo rural en Castilla y León» en Investigando en rural (Baena Escudero, R, et alt., Coord.). Navarra, Ulzama Ediciones, 53-62.

ALBERICH GONZÁLEZ, J. (2009): «Una revisión crítica al concepto de población vinculada según el Censo de Población de 2001. Una aplicación a Catalunya» en Territorio y 
movilidad interior de la población en España (Pons, J. J., Montoro, C., López, D., Barcenilla, M. C., Ed.). Pamplona, Ediciones Universidad de Navarra, 201-208.

CABALlERO, P., DELGADO, J.M. y MARTÍNEZ, L.C. (2012): «La evolución demográfica de Castilla y León: una trayectoria que refleja los rasgos y manifiesta las contradicciones del modelo español», en Población y poblamiento en Castilla y León (Delgado Urrecho, J.M., Dir.). Valladolid, Edit. CES de Castilla y León, 299-528.

DELGADO, J.M. y CABALLERO, P. (2005): La situación de los nuevos yacimientos de empleo en Castilla y León. Valladolid, Edit. CES de Castilla y León.

GARCÍA, J.A., CEBRIÁN, F. Y PANADERO, M. (2008): «El turismo de segunda residencia en el interior peninsular». Scripta Nova. Revista Electrónica de Geografía y Ciencias Sociales, Vol.XII, n' 270.

GOERLICH, F.J. y MÁS, M. (2006): La localización de la población española sobre el territorio. Un siglo de cambios. Un estudio basado en series homogéneas (1900-2001). Bilbao, Edit. Fundación BBVA, 536 pp.

HERNÁNDEZ BORGE, J. (2007): «Población vinculada y residencias secundarias en Galicia». Boletín de la Asociación de Geógrafos Españoles, nº43, 73-84.

INSTITUTO DE ESTUDIOS TURÍSTICOS (2012): Balance del Turismo Año 2011. Resultados de la actividad turística en España. Madrid. IET, Ministerio de Industria, Turismo y Comercio.

INSTITUTO DE ESTUDIOS TURÍSTICOS (2010): FAMILITUR. Encuesta de Movimientos Turísticos de los Españoles. Informe Anual 2010. Madrid. IET, Ministerio de Industria, Turismo y Comercio.

INSTITUTO DE ESTUDIOS TURÍSTICOS (2008): Turismo Interior en Castilla y León en el año 2008. Madrid. IET, Ministerio de Industria, Turismo y Comercio.

INSTITUTO DE ESTUDIOS TURÍSTICOS (2012): COYUNTUR. Boletín trimestral de Coyuntura Turística, $\mathrm{n}^{\circ}$ 9. Madrid. IET, Ministerio de Industria, Turismo y Comercio.

INSTITUTO NACIONAL DE ESTADÍSTICA (2001): Censos de Población y Viviendas 2001. Proyecto. Madrid, INE.

LÓPEZ, J. Y MÓDENES, J.A. (2004): «Vivienda secundaria y residencia múltiple en España: una aproximación sociodemográfica». Scripta Nova. Revista Electrónica de Geografía y Ciencias Sociales, Vol. VIII, nº 178.

MINISTERIO DE FOMENTO (2010): Atlas Estadístico de la Construcción en España. Madrid, Edit. Secretaría General Técnica, Ministerio de Fomento.

MINISTERIO DE VIVIENDA (2011): Informe sobre el stock de vivienda nueva en 2010. Madrid.

RODRÍGUEZ-SALMONES, N., ARANDA, E. Y GARRIDO, B. (2003): «El alojamiento turístico privado en el contexto del sistema de estadísticas de turismo». Estudios Turísti$\cos , \mathrm{n}^{\circ} 155-156,7-32$.

VINUESA ANGULO, J. (2005): «De la población de hecho a la población vinculada». Cuadernos Geográficos, nº 36, 79-90. 
